\title{
NOTES ON ORTHOGRAPHY AND TRANSLATION
}

Place names are written as they appear on maps - thus, Ségou rather than Segu. For personal names, I have generally followed orthographic selfrepresentation rather than use other more recently adopted orthographic conventions - thus, Seydou rather than Seedu and Tall rather than Taal. In a few cases, I have used newer orthographic conventions to aid readers with pronunciation - thus, Cerno and Jakhite, rather than Tierno (or Thierno) and Diakhité. In other cases, I have opted for commonly used orthographies that also more closely approximate pronunciation of local names - thus, Hamallah rather than Hamahoullah or other such variants. For transliteration of words from Bambara, Fulfulde and Soninke, I have, when possible, followed orthographic conventions used by the DNAFLA, Direction nationale d'alphabétisation fonctionnelle et de la linguistique appliquée, in Mali. For transliteration of words from the Arabic, I have used a simplified system with plurals sometimes indicated by adding an ' $s$ ' to the transliterated word, for example, muqaddam (s.) and muqaddams (pl.). Finally, for certain personal names from the Arabic, I have followed the standard transliteration system from Arabic, though I have altered them slightly to more closely approximate local pronunciations - thus, Umar and Amadu, rather than 'Umar and Ahmad.

All translations are my own, except when otherwise noted. 